\title{
Content Classification System Term Indicator
}

National Cancer Institute

\section{Source}

National Cancer Institute. Content Classification System Term Indicator. NCI Thesaurus.

Code C114455.

An indicator of a particular meaning of a term in relation to the Content Classification System. 